\title{
Reducing Defects in RCC Member by using Six Sigma Principle
}

\author{
Neha Bagdiya ${ }^{1}$, Sneha Sawant ${ }^{2}$ \\ ${ }^{1}$ Pad. Dr. D.Y. Patil Institute of Engineering Management \& Research, Akurdi, Pune - 44, Maharashtra, India
}

\begin{abstract}
Six Sigma is a Quality improvement technique that has being implemented in manufacturing and other industries. Six sigma is new to construction industry. This paper describes the basic theory of Six Sigma, principles, methodology and various tools used for reducing defects. A case study of a residential building is taken in which the DMAIC principle is applied for reducing defect in RCC members, the Six Sigma methodology has been adopted to improve the quality. The findings suggest that proper training and management support and minor changes in current work procedure can help improve the quality and ultimately customer satisfaction which is of prime importance.
\end{abstract}

Keywords: Quality Control; Construction defects, DMAIC, SPSS

\section{Introduction}

Quality Management is defined as any approach used to achieve and sustain a high quality output by conforming to requirements and meeting customer satisfaction. Six sigma is a quantitative approach for improvement with the goal of eliminating defects from any process, specifically a numerical goal of 3.4 defects per million opportunities (DPMO). Six sigma is reportedly easier to apply than many other quality management programs because it provides information about the change needed and the programs to execute the change. The strategy it uses is a five-step improvement process: define, measure, analyze, improve and control (DMAIC). This process is deeply integrated with the overall goals of the organization and, as such, requires top down implementation. Six sigma is more intense, focused and detailed than any other quality improvement techniques. Six Sigma was first used in 1985 by Bill Smith of Motorola to decrease cost, increase quality by improving process and reduce the production time.

\section{Statistical Theory behind Six Sigma}

Six Sigma is a statistics based methodology and relies on the scientific method to make significant reductions in customer defined defect rates in an effort to eliminate defects from every product, process and transaction. The Six Sigma principle can be represented on a normally distributed product quality distribution curve. When the mean is located at the center of the normal distribution curve, the lower and upper limits are six times the standard deviation (sigma) from the center line. In other words the range of lower and upper limit defect is +/- 6 sigma from the mean. Table. 1 illustrates the rate of defects per million opportunities in different sigma levels.

Table 1: Overview of Table

\begin{tabular}{|c|c|c|}
\hline Yield & DPMO & Sigma Level \\
\hline 30.9 & $6,90,000$ & 1 \\
\hline 69.2 & $3,08,000$ & 2 \\
\hline 93.3 & 66,800 & 3 \\
\hline 99.4 & 6,210 & 4 \\
\hline 99.98 & 320 & 5 \\
\hline 99.9997 & 3.4 & 6 \\
\hline
\end{tabular}

\section{Basic Framework of Six Sigma Principle}

Based Management According to the paper presented by Seung Heon Han, Myung Jin Chae, Keon Soon Im, Ho Dong Ryu[1] named "Six Sigma Based Approach to Improve Performance in Construction Operations" the six sigma principle concept can be applied to the construction process control within the basic framework of CTQ inputs, DMAIC procedures and output measures as shown in figure below,

\begin{tabular}{|c|c|c|}
\hline Performance & Six Sigma & Indices of Performance \\
Indicators & Application & improvements (outputs) \\
(Input CTQ) & Procedure DMAIC & \\
\hline
\end{tabular}

\section{DMAIC Procedure}

As per paper published by Muharrem Firat Yilmaz[3] named "Six Sigma within Construction Context" Six Sigma is a continuous improvement methodology which known as DMAIC (define, measure, analyze, improve, control) aims to enhance the efficiency of the existing processes and increase customer satisfaction through designed products and services. DMAIC framework is a integration of several techniques such as QFD (quality function deployment), SPC (statistical quality control), DOE (design of experiments), and FMEA (failure mode and effects analysis) in a logical direction. This approach is more suitable when the current design of the products, services and processes are correct and satisfactory regarding to the requirements, customers and business. This methodology offers structured framework in following steps to establish systematic continuous improvement.

Define: In this step it is necessary to define customer requirements and any things do not meet those requirements known as defect, determine key processes, key roles and team charter, define project goals and scope, and estimate the risks and financial impact.

Measure: Identify and collect the appropriate data which are relevant to the defects and the processes need improvement. Measure the processes performance and establish the measurement system based on Six Sigma techniques and tools. 


\section{International Journal of Science and Research (IJSR) \\ ISSN (Online): 2319-7064 \\ Index Copernicus Value (2013): 6.14 | Impact Factor (2014): 5.611}

Analyze: Study and analyze the data collected in previous step to find out the root causes of the defects and unsatisfactory performance.

Improve: Identify alternative solutions and methods based on the knowledge derived from analyze step, study and assess the potential solutions to distinguish the most successful improvement solution. Implement that successful method.

Control: Establish a control plan to ensure that expected improvement has been achieved, and the knowledge and experiences have been documented and shared to remain at attained high level performance.

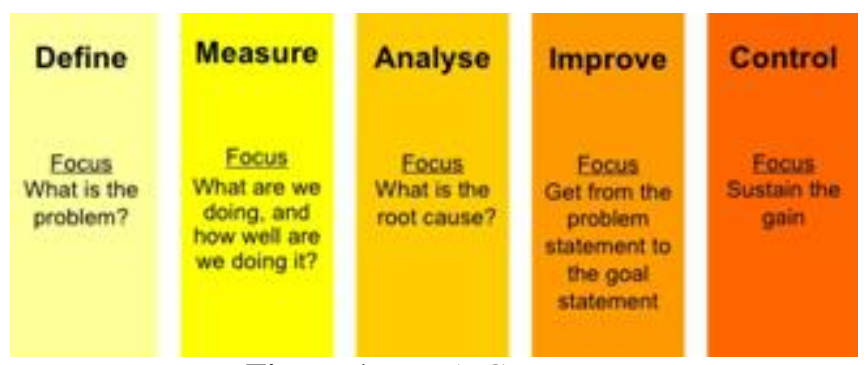

Figure 1: DMAIC Process

\section{Methodology}

For the present study, residential building at Wagholi, Pune is selected to find out the causes of construction defects. There is increasing growth in construction industry in Pune and similar kinds of project are going on in the locality The cost incurred due to defect is high so the causes of construction defects and remedial measures for it is very important to study to a large extent.

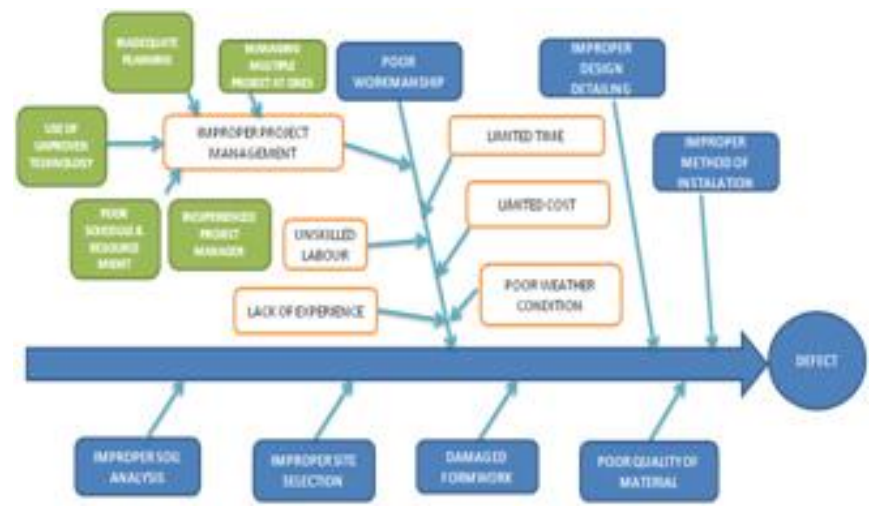

Figure 2: Cause and Effect Diagram

For the case study, checklist was prepared for all the RCC members and the percentage defects were found out. Table below shows the percentage defects.
Table 2: Percentage defects in RCC members

\begin{tabular}{|c|c|c|c|c|}
\hline Origin & Type of defects & $\begin{array}{c}\text { No of } \\
\text { Observations }\end{array}$ & $\begin{array}{c}\text { No of } \\
\text { defects }\end{array}$ & $\%$ defects \\
\hline Column & Cracks & 50 & 05 & $10 \%$ \\
\hline column & Honey- combing & 50 & 20 & $40 \%$ \\
\hline Beam & Cracks & 50 & 02 & $4 \%$ \\
\hline Beam & Honey combing & 50 & 15 & $30 \%$ \\
\hline slab & Cracks & 10 & 5 & $50 \%$ \\
\hline Slab & Honey combing & 10 & 2 & $20 \%$ \\
\hline
\end{tabular}

For measuring the defects Pareto chart was used. Figure below shows the Pareto analysis.

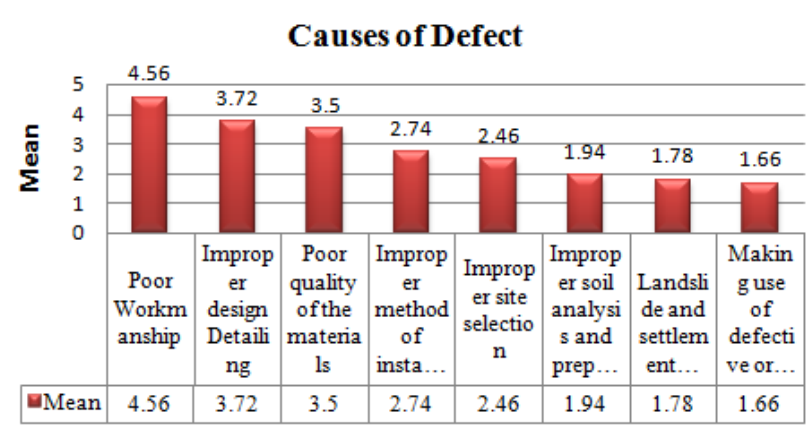

Figure 3: Pareto analysis

The analysis was done using Spearman Correlationship:

Spearman rank correlation is a non-parametric test that is used to measure the degree of association between two variables. It was developed by Spearman, thus it is called the Spearman rank correlation. Spearman rank correlation test does not assume any assumptions about the distribution of the data and is the appropriate correlation analysis when the variables are measured on a scale that is at least ordinal. The following formula is used to calculate the Spearman rank correlation

$$
\rho=1-\frac{6 \sum d_{i}^{2}}{n\left(n^{2}-1\right)}
$$

Where:

$\mathrm{P}=$ Spearman rank correlation

$\mathrm{di}=$ the difference between the ranks of corresponding values $\mathrm{Xi}$ and $\mathrm{Yi}$

$n=$ number of value in each data set

Use Spearman rank correlation when we have two ranked variables, and we want to see whether the two variables co vary whether, as one variable increases, the other variable tends to increase or decrease. We can also use Spearman rank correlation if you have one measurement variable and one ranked variable; in this case, you convert the measurement variable to ranks and use Spearman rank correlation on the two sets of ranks. 
International Journal of Science and Research (IJSR)

ISSN (Online): 2319-7064

Index Copernicus Value (2013): 6.14 | Impact Factor (2014): 5.611

\begin{tabular}{|c|c|c|c|c|c|c|c|c|}
\hline Correlation Result & & $\begin{array}{l}\text { Strict } \\
\text { Supervision }\end{array}$ & $\begin{array}{l}\text { Proper } \\
\text { communi } \\
\text { cation } \\
\text { among } \\
\text { parties } \\
\text { involved }\end{array}$ & $\begin{array}{l}\text { Truiring } \\
\text { and } \\
\text { Edacatio } \\
\text { a }\end{array}$ & $\begin{array}{l}\text { Proper } \\
\text { Construct } \\
\text { ion } \\
\text { Manage } \\
\text { ment }\end{array}$ & $\begin{array}{l}\text { Proper } \\
\text { Manpowe } \\
\text { I } \\
\text { Managem } \\
\text { ent }\end{array}$ & $\begin{array}{l}\text { Proper } \\
\text { Design }\end{array}$ & $\begin{array}{l}\text { Proper } \\
\text { phanning }\end{array}$ \\
\hline & Mean & 4.24 & 3.7. & 262 & 2.46 & 2.14 & 208 & 1.64 \\
\hline Improper project management & 4.3.3. & 0.0196 & 0.4624 & 3.0976 & 3.6864 & 5.0176 & 5.29 & 7.3076 \\
\hline Linskilled labour & 3.36 & 0.7744 & 0.1156 & 0.5476 & 0.81 & 1.4884 & 1.6384 & 2.9584 \\
\hline Lack of communication & 2.84 & 196 & 0.7396 & 0.0484 & 0.1444 & 0.49 & 0.5776 & 1.44 \\
\hline Lack of experience & 2.4 & 3.3856 & 1.69 & 0.0484 & 0.0036 & 0.0676 & 0.1024 & 0.5776 \\
\hline Limited time & 1.7 & 6.4516 & 4. & 0.8464 & 0.5776 & 0.1936 & 0.1444 & 0.0036 \\
\hline Limited cost & 1.62 & 6.8644 & 4.3264 & 1 & 0.7056 & 0.2704 & 0.2116 & 0.0004 \\
\hline \multirow[t]{7}{*}{ Poor weather condition } & 1.6 & 69696 & 4.41. & 0.36 & 0.7396 & 0.2916 & 0.2304 & 0.0016 \\
\hline & Sum & 26.4252 & 15.744 & 5.9484 & 6.6672 & 7.8192 & 8.1948 & 14.1292 \\
\hline & & 1] & 1] & 1 & 1 & 1 & 1 & 1 \\
\hline & $6 * 5 d^{\prime 2}$ & 1585512 & 94,464 & 35.6904 & 40.0032 & 46.9152 & 49.1688 & 84.7752 \\
\hline & $N(N-2-1)$ & 336 & 336 & 336 & 336 & 336 & 336 & 336 \\
\hline & & 0.471879 & 0.28114 & 0.10622 & 0.11906 & 0.139629 & 0.14634 & 0.25231 \\
\hline & Corelation & 0.528121 & 0.71886 & 0.89378 & 0.88094 & 0.860371 & 0.85366 & 0.74769 \\
\hline
\end{tabular}

Figure 4: Spearman Correlation

\section{Conclusion}

By using DMAIC procedure of Six sigma it is found that for construction defects and failures, poor workmanship is most common factor that leads to construction defects and failures. Therefore, it is important to ensure skilled and experienced labor to overcome the causes of defects. In addition, it is recommended that to reduce this type of defect, training and education should be provided to the labors for doing good work. The relationship between measures identified with factors contribute to poor project/construction management was examined by using correlation testSpearman's rho. Measures identified can be applied to the factors which have significant relationship with them based on the results of correlation test (Spearman rank correlation coefficient) in order to solve the poor workmanship problem

\section{References}

[1] Paper presented on Six Sigma-Based Approach to Improve Performance in Construction Operations Seung Heon Han, M.ASCE1; Myung Jin Chae, Ph.D., P.E.; Keon Soon Im, P.E.; and Ho Dong Ryu

[2] N. Ahzahar, N.A. Karim, S.H. Hassan, J. Eman “A Study of Contribution Factors to Building Failures and Defects in Construction Industry"

[3] Benefits, obstacles and future of Six Sigma approach by Young Hoon Kwak and Hrank T. Anbari.

[4] Wai-Kiong Chong, M.ASCE and Sui-Pheng Low "Assessment of Defects at Construction and Occupancy Stages".

[5] A.S. Ali \& K. H. Wen, "Building Defects: Possible solution for poor construction workmanship".

[6] H. Aljassmi, J. Perera, and S. Han, "Identifying and Analyzing the Correlations and Inter-Causalities of the Root Causes of Construction Defects".

[7] By A. M. EI-Shahhat,t D. V. Rosowsky,Associate Member, ASCE, andW. F. Chen, Member, ASCE," Accounting for Human error during Design and Construction".
[8] Nuria Forcada, Marcel Macarulla; and Peter E. D. Love," Assessment of Residential Defects at Post-Handover".

[9] Wei Pan and Rhys Thomas" Defects of New-Build Dwellings Constructed to Building Regulations and to the Code for Sustainable Homes." 